\title{
High resolution neurochemical gold staining method for myelin in peripheral and central nervous system at the light- and electron- microscopic level
}

\section{Journal Article}

Author(s):

Savaskan, Nic E.; Weinmann, Oliver; Heimrich, Bernd; Eyupoglu, Ilker Y.

Publication date:

2009-08-01

Permanent link:

https://doi.org/10.3929/ethz-b-000086174

Rights / license:

In Copyright - Non-Commercial Use Permitted

Originally published in:

Cell \& Tissue Research 337(2), https://doi.org/10.1007/s00441-009-0815-9 


\title{
High resolution neurochemical gold staining method for myelin in peripheral and central nervous system at the light- and electron-microscopic level
}

\author{
Nic E. Savaskan • Oliver Weinmann • Bernd Heimrich • \\ Ilker Y. Eyupoglu
}

Received: 2 February 2009 /Accepted: 28 April 2009/Published online: 10 June 2009

(C) Springer-Verlag 2009

\begin{abstract}
Myelin is a multilamellar membrane structure primarily composed of lipids and myelin proteins essential for proper neuronal function. Since myelin is a target structure involved in many pathophysiological conditions such as metabolic, viral, and autoimmune diseases and genetic myelin disorders, a reliable myelin detection technique is required that is equally suitable for light- and electron-microscopic analysis. Here, we report that single myelinated fibers are specifically stained by the gold phosphate complex, Black gold, which stains myelin in the brain, spinal cord, and peripheral nerve fibers in a reliable manner. Electron-
\end{abstract}

This study was supported by grants from the International Human Frontier Science Program Organization (HFSPO, to N.E.S.) and the Danone Institute (to N.E.S. and I.Y.E.).

\footnotetext{
N. E. Savaskan $(\bowtie) \cdot$ O. Weinmann

Brain Research Institute,

Swiss Federal Institute of Technology (ETH) and University Zurich,

Winterthurerstrassse 190,

CH-8057 Zurich, Switzerland

e-mail: savaskan@gmx.net

N. E. Savaskan

Institute of Cell Biology and Neurobiology,

Center for Anatomy CCM,

Charité University Medical School Berlin,

D-10115 Berlin, Germany

B. Heimrich

Zentrum für Neurowissenschaften and Institute of Anatomy

\& Cell Biology I, Albert Ludwigs University of Freiburg,

D-79104 Freiburg, Germany

I. Y. Eyupoglu

Department of Neurosurgery, University of Erlangen-Nuremberg,

D-91054 Erlangen, Germany
}

microscopic and morphometric analyses have revealed that gold particles are equally distributed in the inner, compact, and outer myelin layers. In contrast to Luxol fast blue, the gold dye stains proteinase-sensitive myelin structures, indicating its selective labeling of myelin-specific proteins. Aiming at defining the target of gold staining, we performed staining in several mouse myelin mutants. Gold complex distribution and myelin staining in $\mathrm{MBP}^{-/}$/shiverer mouse mutants was comparable with that seen in wild-type mice but revealed a more clustered Black gold distribution. This gold staining method thus provides a sensitive and specific high-resolution marker for both central and peripheral myelin sheaths; it also allows the quantitative analysis of myelinated fibers at the light- and electron-microscopic level suitable for investigations of myelin and axonal disorders.

Keywords Neurohistopathological staining technique . Myelin · Demyelinating disease · Central nervous system . Peripheral nervous system · Reticulon-4/Nogo A · Myelin associated glycoprotein (MAG) .

Mouse (shiverer mutant)

\section{Introduction}

Myelin in the central nervous system (CNS) is an essential structure for the proper functioning of neuronal signal transmission. This specialized structure surrounding axons exhibits a multilamellar, spirally wrapped extension of the plasma membranes originating from oligodendrocytes in the CNS and of Schwann cells in the peripheral nervous system (PNS; Morell et al. 1994). Serving as an axonal insulator, myelin sheaths allow saltatory impulse conduc- 
tion and thereby reduce energy and space expenditure by the nerve cell (Henderson et al. 2001). However, myelin also exhibits growth-inhibitory properties for axons that have been shown to contribute to lack of functional recovery following neurotrauma (for a review, see Yiu and $\mathrm{He}$ 2006). The clinical significance of myelin is reflected by its disturbance in CNS pathologies such as immune-mediated, virus-mediated, metabolic, and inherited demyelinating diseases (Lazzarini 2004).

Over $70 \%$ of the dry weight of myelin consists of lipids (Cammer and Norton 1976), and the remainder comprises myelin-specific proteins such as myelin-associated glycoprotein (MAG), oligodendrocyte-myelin glycoprotein (Omgp), myelin basic protein (MBP), proteolipid protein (PLP), 2',3'-cyclic nucleotide phosphodiesterase, protein $\mathrm{P}_{0}$, PMP-22, and reticulon-4 (Rtn-4)/Nogo (Campagnoni and Macklin 1988; Smith 1992; Taylor et al. 2004; Dumont et al. 2007). A common approach for the detection of myelin is antibody-based immunocytochemistry staining for surrogate marker proteins of oligodendrocytes and myelin-specific proteins. However, the disadvantage of this approach is the requirement for specific antibodies suitable for immunostaining, and hence, the dynamic expression of the antigen of interest during the course of development and injury impacts staining results. A conceptually different approach aims to detect the specific lipid composition of myelin. Thus, many existing methods for myelin staining are based upon a high affinity to myelin lipids and nonsoluble phospholipids: diamine silver (Gallyas 1979), Sudan black (Meier 1976), potassium dichromate hematoxylin stain (Weigert 1884), Oil red O, or Luxol fast blue (LFB; Kluver and Barrera 1953). However, when single fiber resolution is required, these staining approaches do not meet the necessary contrast and resolution quality. For these aspects, silver staining techniques first developed by Gallyas (1979) are utilized and remain, with modifications, the standard (Pistorio et al. 2006). Other than its applicability for postembedding procedures, the disadvantages of this technique are the unpredictability of the signal-to-noise ratio (time of development and background), the significant time input, and the complex staining procedure.

By comparison, gold-based staining techniques represent an alternative that meets the criteria of high resolution and reproducibility (Meier et al. 2003, 2004; Schmued and Slikker 1999). In this study, we have performed a morphometric and ultrastructural analysis of myelin in the PNS and CNS by using an improved gold-based staining method (product launched as Black gold; BG) and have investigated the target of gold-particle staining. We show that BG stains all myelin layers with the same affinity (inner, compact, and outer myelin layers), independently of the axonal diameter. In addition, the structures showing affinity for BG are mostly proteinase-sensitive, indicating that the gold complex stains myelin-specific proteins or protein-lipid complexes. To unravel the molecular target of gold affinity further, we have tested various mouse strains deficient for myelin proteins such as MAG, NogoA (Rtn-4) and shiverer/MBP.

Our data reveal that BG stains myelin sheaths of mature axons in the adult brain and myelin in peripheral nerves. Furthermore, the gold stain detects subtle alterations in myelin in genetically modified animals such as in shiverer mice. Thus, we provide here a simple method for staining myelin at high resolution and contrast at the single fiber level suitable for the detection of myelin under neuropathological conditions.

\section{Materials and methods}

\section{Animals and tissue preparation}

Wistar male rats (200-300 g body weight) and adult wildtype and mutant mice (Shiverer/ $\mathrm{MBP}^{-/-}, \mathrm{MAG}^{-/-} ; \mathrm{NogoA}^{-/}$ (Rtn-4), MAG/NogoA double mutants) housed under standard laboratory conditions. Animals were deeply anesthetized with an overdose of the anesthetic mixture of Ketanest (Gödecke/Park-Davis, Germany), Rompun (Bayer, Germany), and Ventranquil (Sanofi-Ceva, Germany) and transcardially perfused with $200 \mathrm{ml}$ saline followed by $250 \mathrm{ml} \%$ paraformaldehyde (PFA) containing $0.2 \%-2 \%$ glutaraldehyde dissolved in $0.1 \mathrm{M}$ phosphate buffer (PB) for gold phosphate (BG) staining. The tissue was postfixed in $20 \%$ sucrose in $4 \%$ PFA solution for 2 days, shock-frozen in the gaseous phase of liquid nitrogen, and stored at $-80^{\circ} \mathrm{C}$. Animals used for LFB staining were decapitated, after which the brains, sciatic nerves, spinal cord, kidney, and liver were immediately removed, frozen, and stored at $-80^{\circ} \mathrm{C}$. All sections were cut on a cryostat microtome (Leica) at a thickness of 20-50 $\mu \mathrm{m}$.

Myelin staining technique with gold particles

A $0.2 \%$ working solution of gold chloride $\left(\mathrm{AuCl}_{4}\right.$; Merck, Darmstadt, Germany) or gold phosphate (BG granulate; Histo-Chem, Jefferson, USA) was prepared in $0.9 \% \mathrm{NaCl}$, briefly heated at $60^{\circ} \mathrm{C}$, and, for full equilibration, stored in the dark overnight at room temperature. Cryocut sections were washed with $0.1 \mathrm{M} \mathrm{PB}$ and subsequently stained with $0.2 \%$ gold phosphate solution, warmed to $45-60^{\circ} \mathrm{C}$, for 15 to $40 \mathrm{~min}$ according to Jabonero (1953). To intensify the staining, the sections were incubated in $0.2 \%$ potassium tetrachloroaureate (Sigma-Aldrich Chemie, Germany) dissolved in $0.9 \% \mathrm{NaCl}$ for $15 \mathrm{~min}$. For fixation, sections were incubated for $3 \mathrm{~min}$ in 2\% sodium chlorate (Merck) dissolved in $0.9 \% \mathrm{NaCl}$. This procedure proved suitable for the myelin staining of free-floating sections, giving the same results as on sections attached to slides, and allowed counterstaining to be performed. Sections were stained for 
$1.5 \mathrm{~min}$ in a $0.1 \%$ acetic acid solution of $0.4 \%$ malachite green (Sigma-Aldrich Chemie), rinsed in distilled water for $1 \mathrm{~min}$, and differentiated in $70 \%$ ethanol to remove background staining. In between each step, the sections were carefully rinsed three times in $0.1 \mathrm{M}$ PB for $5 \mathrm{~min}$. The free-floating sections were mounted on SuperFrostPlus slides (Menzel-Glaeser, Berlin, Germany), air-dried, dehydrated in graded ethanol, cleared in xylene, and coverslipped with Entellan (Merck).

\section{LFB staining}

The tissue was postfixed in $-20^{\circ} \mathrm{C}$ cold methanol for $2 \mathrm{~min}$ and then transferred to an ethanol/acetic acid mixture (96\%/ $4 \%$ ) for $5 \mathrm{~min}$. Sections were stained in a $0.1 \% \mathrm{LFB}$ solution dissolved in the same ethanol/acetic acid mixture at $60^{\circ} \mathrm{C}$ for $3 \mathrm{~h}$, rinsed in $96 \%$ ethanol, postfixed in $0.05 \%$ $\mathrm{Li}_{2} \mathrm{CO}_{3}$ for $1 \mathrm{~min}$, washed in $70 \%$ ethanol for a few seconds, counterstained with Harris' hematoxylin for 12 min, dehydrated in graded ethanol, and coverslipped with Entellan (Merck).

\section{Protein digestion}

Sections were incubated with $50 \mu \mathrm{g} / \mathrm{ml}$ proteinase $\mathrm{K}$ (Boehringer, Germany) dissolved in $0.01 \mathrm{M}$ TRIS ( $\mathrm{pH}$ 8.0 ) and $0.1 \% \mathrm{SDS}$ at $37^{\circ} \mathrm{C}$ for $40 \mathrm{~min}$ or with $0.25 \%$ trypsin in a dilution buffer containing $0.04 \% \mathrm{KCl}, 0.22 \%$ $\mathrm{NaHCO}_{3}, 0.68 \% \mathrm{NaCl}, 0.1 \%$ glucose and then stained with $\mathrm{BG}$ or LFB as discribed above.

\section{Electron microscopy}

BG sections were osmicated $\left(1 \% \mathrm{OsO}_{4}\right.$ in $6.84 \%$ sucrose/ PB for $5 \mathrm{~min}$ ), dehydrated in graded ethanol, and flatembedded in Epon between silane-coated slides. Ultrathin sections were cut on a Reichert Ultratome (Germany), mounted on single-slot grids coated with Formvar film, and stained with lead citrate and uranyl acetate. A Zeiss EM 900 electron microscope was used for examination, and microphotographs were taken with a digital camera (Zeiss, Jena, Germany).

Quantification of myelinated fibers and axonal diameters

For densimetric measurements of the myelinated fibers, we used a computerized videodensitometry system (MetaMorph, Universal Imaging, Downingtown, Pa., USA). A visually established pixel intensity threshold was set to remove the unlabeled portion of the image. Statistical analysis was performed with the Mann-Whitney $U$-test (StatViewII, Abacus, USA). The levels of significance were set at $* P<0.05, * * P<0.01$, and $* * * P<0.001$.

\section{Results}

Myelinated fibers in CNS detected with gold staining

First, we assessed BG staining on brain sections of adult rats. BG staining specifically appeared as red-brown coloration in white matter areas at low resolution, whereas gray matter areas were stained to a lower extent, in parallel with their myelin content (Fig. 1). The BG staining suitably reflected the myeloarchitecture of the CNS, staining the main white matter tracts such as corpus callosum and anterior commissure (Fig. 1a, b). In addition, higher magnification revealed single thin gold-positive fibers in the cortex and olfactory bulb, whereas neuronal cell bodies remained unstained (Fig. 1b-d). In the cortex, the majority of stained myelinated axons were vertically oriented. BG stain uncovered cortical neurites intermingled with horizontally running fibers, which formed a fine dense network (Fig. 1e, f). Staining of the entorhinohippocampal formation visualized both the afferent and efferent axonal projections, such as the perforant path, alveus, and the fimbria-fornix system (Figs. 1, 2). Staining intensity varied in between the various hippocampal subfields reflecting the laminar organization of the fiber projections, e.g., the strong gold labeling in the stratum lacunosum-moleculare of the cornu ammonis 1 (CA1) and stratum radiatum of CA1-CA3 (Fig. 2a). Myelinated fibers formed a dense network in the neuropil and were often observed surrounding the neuronal somata of the granule and pyramidal cells (Fig. 2b). Electron-microscopic analysis revealed single gold particles distributed along myelin sheaths (Fig. 2c). Other subcellular structures and organelles, such as mitochondria, nuclei, or endoplasmic reticulum, remained unstained (Figs. 2, 3). Subsequent quantitative analysis revealed that gold particles surrounded mature axons and were equally distributed in the inner, compact, and outer layers of the myelin spirals ( $33 \pm 8$ particles $/ 5 \mu \mathrm{m}^{2}$; mean \pm S.D., Mann-Whitney $U$-test). Gold particles were also located along myelin sheaths surrounding axons of various diameters ranging from $120 \mathrm{~nm}$ to $260 \mathrm{~nm}$, whereas dendritic processes were BG-negative.

We subsequently analyzed spinal cord sections stained with this dye. Gold-positive fibers could be found in all white matter fiber tracts with prominent staining of descending fibers (i.e., fasciculus gracilis, cerebrospinal and anterior spinothalamic tracts; Fig. 3). Myelinated fibers from the dorsal root entering the gray matter were also positively stained for BG (Fig. 3b). Ultrastructural analysis confirmed the nature of gold-positive fibers as being myelinated (Fig. 3c, d), with gold particles being distributed irregularly along the myelin sheaths without preference for the inner, compact, or outer layers of myelin spirals (Fig. 3c, d). 
Fig. 1 Distribution of Black gold (BG)-positive fibers in the adult CNS. a Overview of a gold-stained coronal brain section. Note the intense staining of fiber tracts such as corpus callosum $(c c)$, anterior commissure $(a c)$, and internal and external capsule. b Higher magnificantion of the corpus callosum $(c c)$. c The lateral olfactory tract (lo) and anterior commissure $(a c)$ show BG-positive fibers in redbrown, whereas the ondulated primary olfactory cortex $(P O)$ is BG-negative ( $C P$ caudate putamen). $\mathbf{d}$ Higher magnification of the olfactory tract shown in $\mathbf{c}$ reveals single myelinated fibers, although neurons in the olfactory cortex (counterstained with malachite green) show no BG staining ( $P O$ primary olfactory cortex). e BG staining of the temporal cortex ( $I-V I$ layers of the cortex). Note the intense labeling of the white matter by BG. In addition, verticaloriented axon profiles are BGpositive ( $w m$ white matter). $\mathbf{f}$ High magnification of e. Bars $1 \mathrm{~mm}(\mathbf{b}), 40 \mu \mathrm{m}$ (c), $220 \mu \mathrm{m}$ (d), $80 \mu \mathrm{m}(\mathbf{e}), 150 \mu \mathrm{m}$ (f)
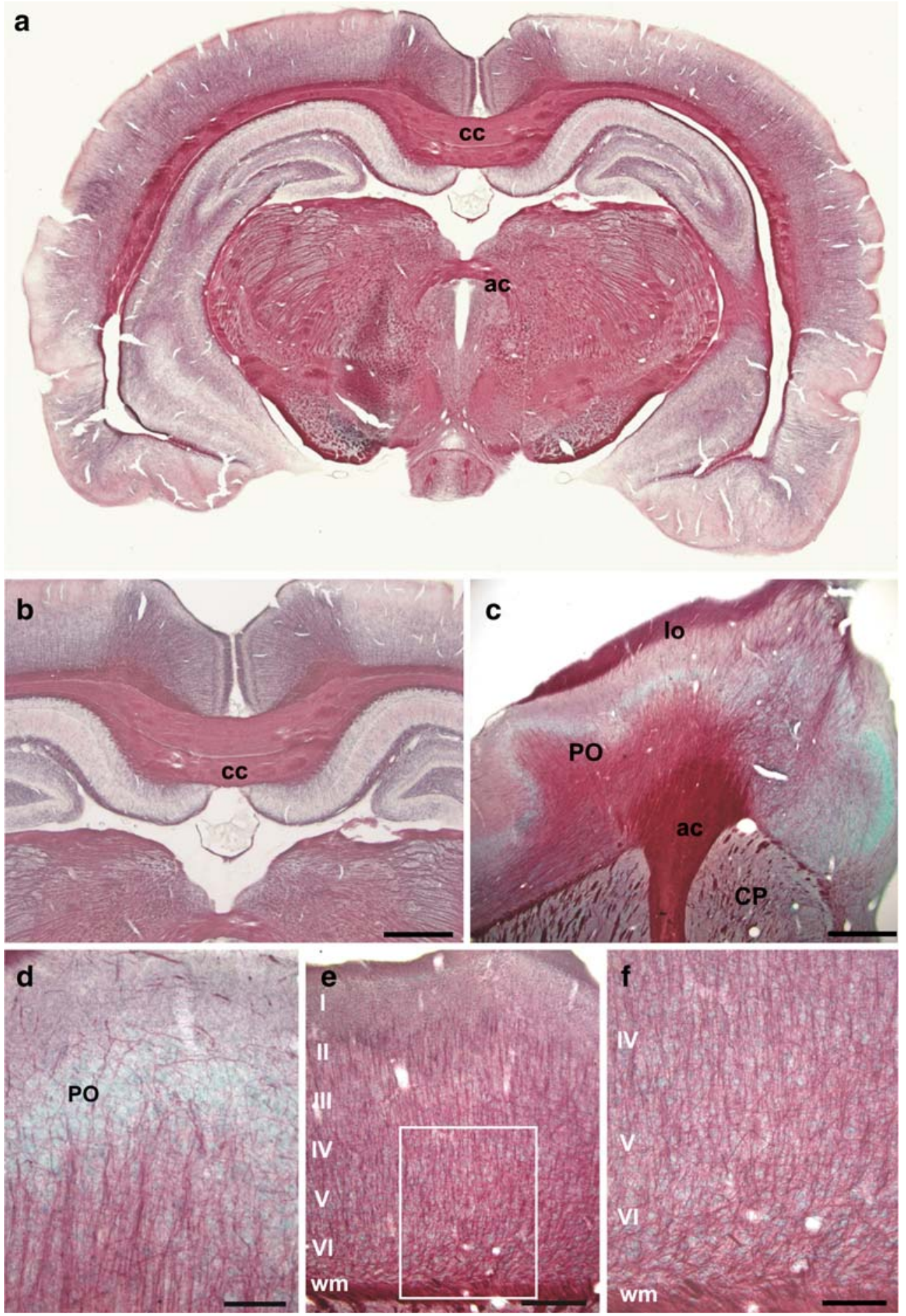

Myelinated fibers in PNS detected with gold staining

Since the composition of peripheral myelin differs remarkably from that found in the CNS (Uyemura et al. 1995; Avila et al. 2007), we have addressed the question as to whether BG is also a suitable dye for myelin detection in the PNS. We therefore stained the sciatic nerve with BG, by applying the same procedure and tissue treatment as above. In the peripheral nerves, the distribution of the gold stain was comparable with that found in CNS myelin. Gold particles were clustered around all myelin sheaths (inner, compact, and outer loops of myelin spirals), whereas the axonal plasma and the extracellular space were almost free of any staining (Fig. 4). Within the myelin structure, non- 
Fig. 2 Light and ultrastructural distribution of BG particles in the adult hippocampus. a Overview of gold-stained adult hippocampus with adjacent entorhinal cortex is shown in (arrows perforant path, $h i$ hilus, $\mathrm{gcl}$ granule cell layer, $C A$ cornu ammonis, $E C$ entorhinal cortex, $\mathrm{pcl}$ pyramidal cell layer, $m l$ molecular layer, $\operatorname{slm}$ stratum lacunosum moleculare). b BG labeling in the dentate gyrus. c BG labeling in the hilus. $\mathbf{d}$ BG labeling in the CA3 region. e Ultrastructural analysis of the stratum lacunosum moleculare reveals BG deposits around mature axons in the inner, compact, and outer layers of myelin. Mitochondria (stars), axoplasma $(a x)$, and nuclei are devoid of BG particles. Bars $700 \mu \mathrm{m}(\mathbf{a})$, $20 \mu \mathrm{m}(\mathbf{b}-\mathbf{d}), 3 \mu \mathrm{m}(\mathbf{e})$
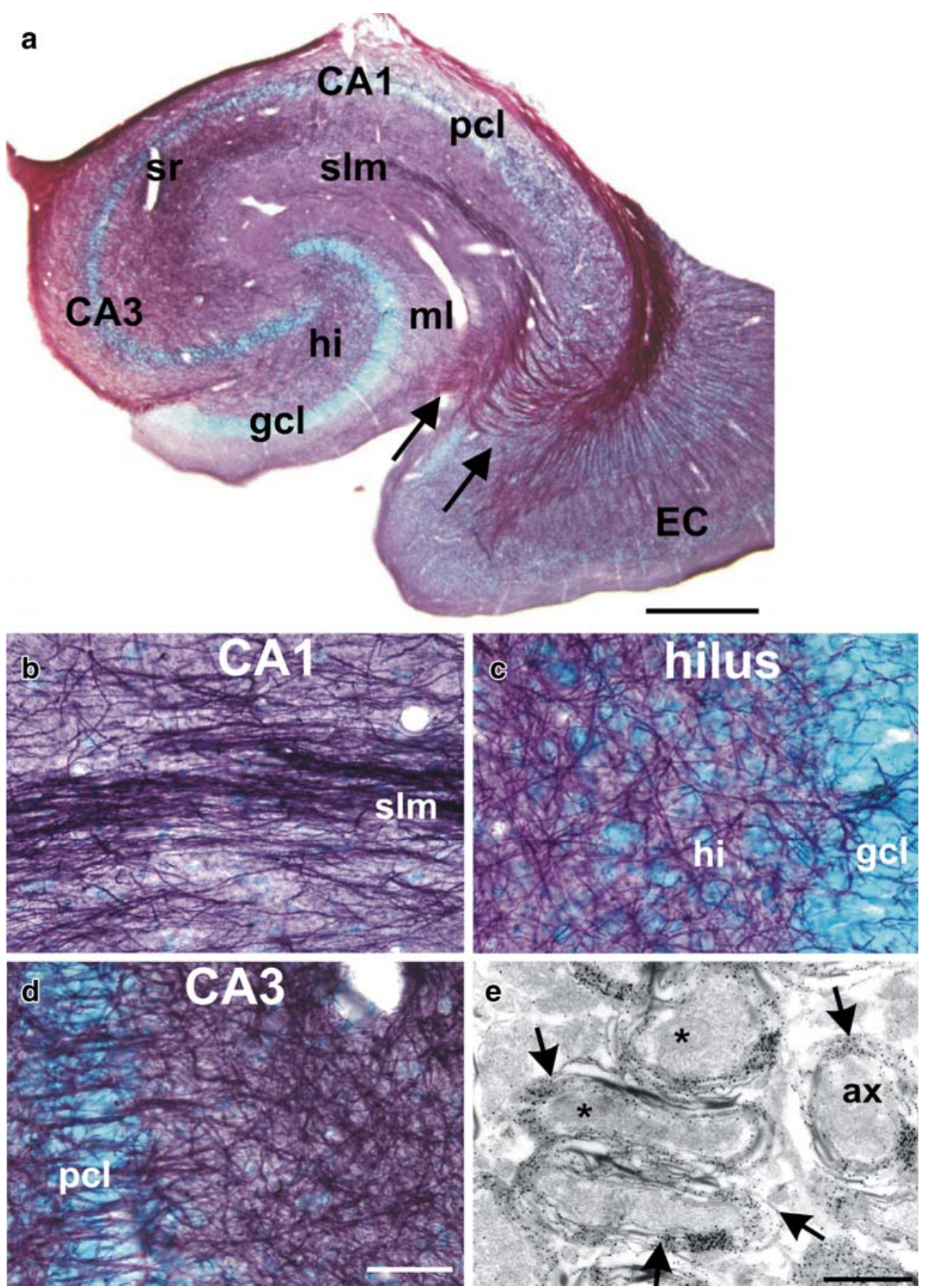

compact myelin such as Schmidt-Lanterman incisures and Schwann cell cytoplasm were almost devoid of BG particles (Fig. 4). Overall, BG staining in peripheral myelin revealed almost the same contrast and staining intensity as that found in CNS myelin structures.

Target of myelin gold-particle staining

To define the molecular target of gold staining, we performed staining of various organs that do not contain myelin components, i.e., muscle, kidney, and liver. None of these tissues showed significant BG staining compared with samples from CNS or PNS (Fig. 5a, b). We therefore assumed that BG stains distinct myelin proteins specifically present in peripheral and central myelin structures. To test this, we utilized brain sections in which proteins were, at least in part, diminished by proteinase $\mathrm{K}$ and trypsin digestion. In such sections, BG staining was completely abolished (Fig. 5c). To control for these results, we used LFB, a dye with high affinity for non-soluble phospholipids 
Fig. 3 Light and ultrastructural distribution of gold particles in the spinal cord. a, b Longitudinal and transversal sections, respectively, of the spinal cord at the thoracical level stained with BG. BG-positive fibers are found in all white matter areas of the spinal cord ( $d$ dorsal columns, il intermediate layer, $v$ ventral columns). c, d Ultrastructural analysis of the spinal cord reveals BG particles (arrows) distributed over the myelin sheaths ( $a x$ axoplasma). d BG-positive fibers entering the gray matter arise from the dorsal roots (top dorsal columns of the spinal cord, stars mitochondria). Bars $500 \mu \mathrm{m}$ (a, b), $4 \mu \mathrm{m}$ (d; applies also to $\mathbf{c}$, magnification $\times 30,000$ )
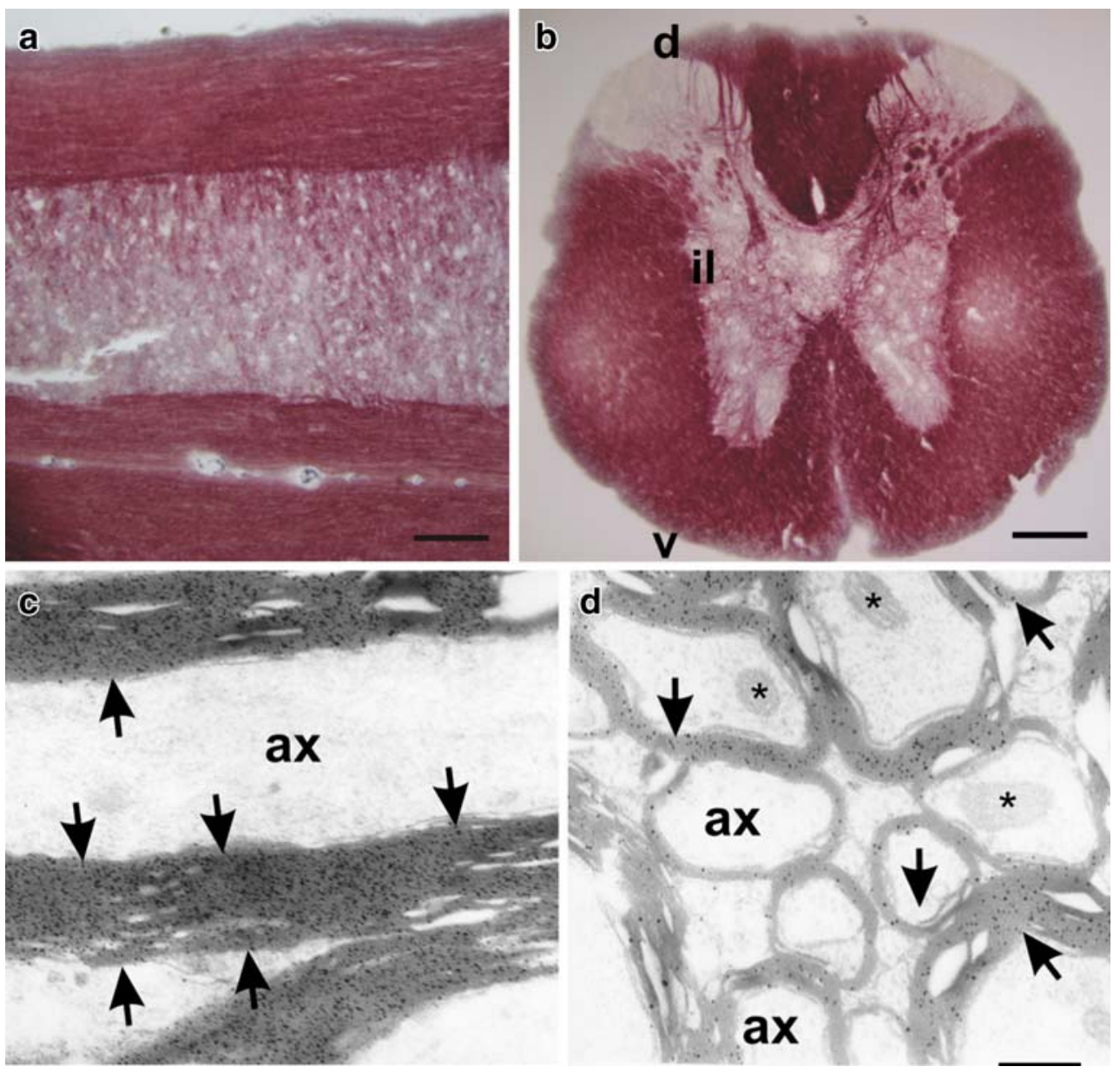

(Kluver and Barrera 1953). As expected, this common myelin marker was unaffected by proteinase pretreatment (Fig. 5d). These data demonstrate that BG stains proteins or protein complexes specifically present in peripheral and central myelin.

These data prompted us to study the gold staining of brain sections from mice mutant for myelin proteins. Thus, in order to define further the molecular target of gold affinity present in myelin, we investigated sections from homozygous shiverer mouse mutants that lack one major myelin protein component, viz., MBP (Dupouey et al. 1979; Kirschner and Ganser 1980). In shiverer/MBPdeficient mice, BG staining was still detectable with the same intensity in white matter areas (Fig. 6). However, in contrast to the regular axon-like staining pattern of the white matter of the spinal cord from wild-type mice, we observed irregular, discontinous, and more concentrated staining and a more clustered distribution of BG stain in shiverer mice (Fig. 6). This could reflect the lightmicroscopic correlate of reduced myelin lamellae sheaths and the membranous debris as found at the ultrastructural level in shiverer animals (Bird et al. 1978; Privat et al. 1979; Kirschner and Ganser 1980; Rosenbluth 1980).
However, since BG stain still remained in MBP-deficient mice, myelin proteins other than MBP are probably the high-affinity targets of gold particles.

\section{Discussion}

In this study, we have investigated, with an improved gold staining procedure, regional distinctions in myelinated fiber distribution in the PNS and CNS and in shiverer mutant mice. We have been able to show that gold dye is suitable for specifically and selectively staining myelin structures in the CNS and PNS with high resolution at the level of single fibers, facilitating axonal analysis at the light and ultrastructural levels.

Studies of myelin in the brain by using histochemical techniques have to be interpreted with some caution. Low signal-to-noise ratio, intensity, contrast, and considerable variability in staining and exposure time and the unknown molecular substrate that is being stained are some of the possible pitfalls and limitations. In addition, many histochemical techniques do not reliably distinguish between normal and pathological myelin structures. In addition, 

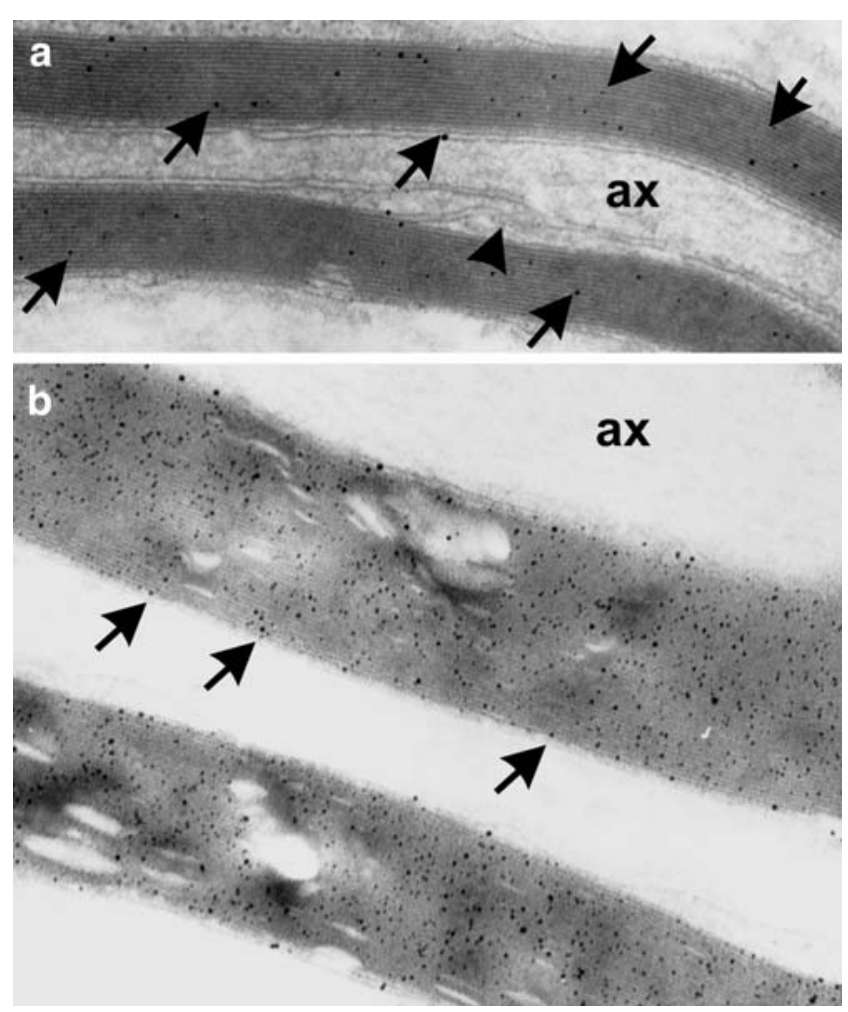

Fig. 4 Distribution of gold staining in the peripheral nervous system. a Longitudinal section of sciatic nerve stained with BG. Particles of BG (arrows) are found in myelin sheaths along the nerve fibers but not in the axoplasma (ax) or extracellular space (arrowhead cytoplasmic Schwann cell process forming an inner mesaxon). b Higher magnification of peripheral myelin sheaths. Gold particles are found in all aspects of the myelin spirals. Magnification: $\times 30,000$ (a), $\times 40,000$ (b)

single fiber resolution is not achieved by some myelin staining procedures such as LFB, and therefore these techniques are insensitive for the assessment of dynamic and subtle axonal pathologies. Here, we have performed sets of experiments with the modified aurohalophosphate BG. Ultrastructural analysis has revealed that the gold complex stains inner, compact, and outer myelin layers with the same affinity, whereas dendritic processes do not stain for gold particles. Furthermore, BG stains all layers of myelin sheaths, independently of axonal diameter, in agreement with our previous studies on hippocampal development (Meier et al. 2003, 2004). In addition, this gold staining method is also applicable to myelin staining in the PNS. Here, we have found that gold grains are centered around all myelin sheaths with same preference as that seen in CNS myelin samples, suggesting that the components with the same affinity for gold particles must be present in both CNS myelin and PNS myelin.

These results have prompted us to test which components are being stained by gold particles. Pretreatment of brain sections with trypsin or proteinase $\mathrm{K}$ prevents $\mathrm{BG}$ staining. Conversely, the staining pattern of the phospholipid specific dye LFB is not affected by these treatments. These findings are not surprising, since the target to which LFB binds with high affinity are non-soluble phospholipids, which are resistant to this treatment (Kluver and Barrera 1953). However, our findings also indicate that BGpositive structures are proteinase-sensitive. These membrane structures may comprise myelin-specific proteins or specific lipid-protein complexes that are present in myelin and that are disrupted after protease treatment. In the first case, these myelin protein components must be located in all myelin layers, or their distribution overlaps in all myelin compartments, since gold complex deposits are found virtually in all myelin layers. This is of relevance since myelin proteins have various localizations. For instance, MAGs and NogoA are mostly located in the inner and outer loop of myelin layers, respectively, and myelin oligodendrocyte glycoprotein in the outer loop (Trapp et al. 1989; Huber et al. 2002). In contrast, MBP, PLP, and $\mathrm{P}_{0}$ are predominantly found in compact central and peripheral myelin. We speculate that MBP might be a target structure recognized by gold particles since it is present in CNS myelin and PNS myelin, in contrast to CNS myelin proteins such as Rtn4/NogoA and Omgp. Thus, we have tested various mouse myelin mutants. Brain samples from $\mathrm{NogoA}^{-/-}, \mathrm{MAG}^{-/-}$, and $\mathrm{NogoA}^{-1-} / \mathrm{MAG}^{-/-}$doublemutant mice show almost no differences compared with wild-type littermates (data not shown) indicating that either these two proteins do not have high affinity for gold particles or do not make up the majority of gold-labeled myelin proteins, and thus, their genetic lack is below detection levels. Shiverer mice, which are mutant for the MBP protein, might be devoid of staining and should serve as a negative control for target identification of gold labeling. However, the overall staining pattern is not altered, although a slight alteration in staining intensity and a clustered distribution of gold-stained fibers are visible at the light microscopic level. These changes in BG staining in shiverer mice might reflect the described altered myelin membrane lamellae and membrane debris found at the ultrastructural level (Bird et al. 1978; Privat et al. 1979; Kirschner and Ganser 1980; Rosenbluth 1980). Central and peripheral myelin is composed of several proteins such as PLP (Campagnoni et al. 1976), MAG (Li et al. 1996; McKerracher et al. 1994; Mukhopadhyay et al. 1994), $\mathrm{P}_{0}$ (Greenfield et al. 1973), Omgp (Wang et al. 2002; Kottis et al. 2002), chondroitin-sulfate proteoglycans (Dou and Levine 1994; Niederost et al. 1999), and Rtn-4/NogoA (Chen et al. 2000; GrandPre et al. 2000; Prinjha et al. 2000), which could all be candidate targets with different affinity for the gold stain. Since gold particles are distributed all over the central and peripheral myeloarchitecture, the gold stain probably has high affinity to more 
Fig. 5 Gold particles are highly specific for myelin and stain proteinase-sensitive myelin components. a BG-treated cross sections of kidney reveal no staining. b BG-positive bundles of fibers in the abducens nerve (arrows single fine myelinated axons). c Following proteinase $\mathrm{K}$ digestion of a brain section, almost no fibers are stained for BG (arrows slight BG-positive staining). d Positive staining with Luxol fast blue (LFB) still appears after proteinase $\mathrm{K}$ digestion (arrowheads border of white matter). LFB staining appears in dark blue (upper region) and the gray matter in light blue (lower region). Hematoxylin-positive nuclei appear as dark blue spots. Bars $10 \mu \mathrm{m}$ (a; applies also to $\mathbf{b})$, $50 \mu \mathrm{m}$ (d; applies also to c)
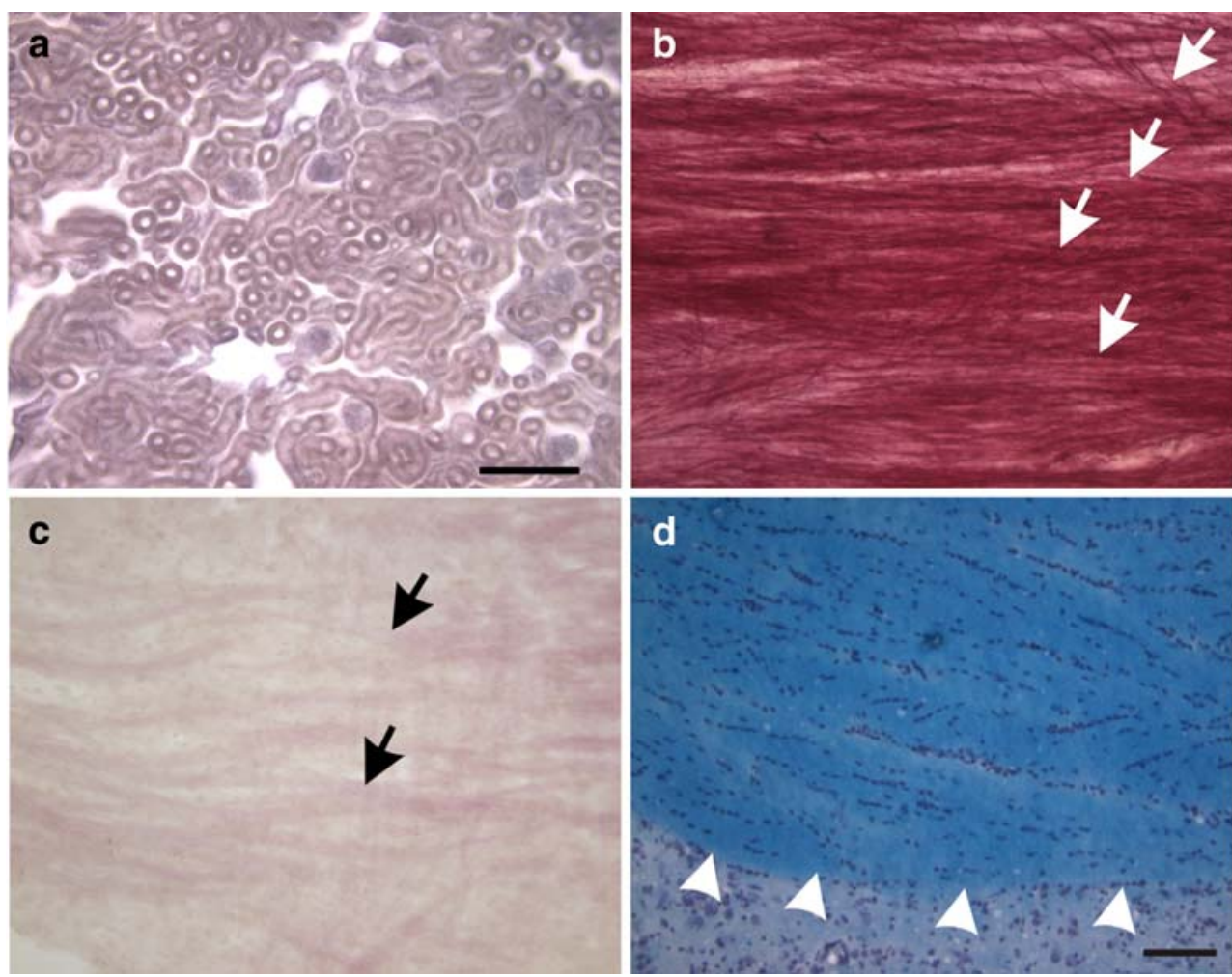

then one myelin-specific protein component present both in $\mathrm{CNS}$ and PNS. Future studies will concentrate on the investigation of gold staining on two major myelin protein components of the PNS and CNS. Analysis of $\mathrm{PLP}^{-/}$and $\mathrm{P}^{-/}$mice should help to define whether lack of these major myelin protein components correlates with an altered gold-particle distribution and intensity at the quantitative level. Indeed, a prerequisite for a novel dye becoming a standard staining method for myelin pathologies would ideally be knowledge of its target and its intensity correlation with disease progression. In myelin disorders, myelin proteins might be mislocated or altered in abundance, or myelin spirals might be disturbed with regard to their thickness or ultrastructure. We thus need to show that BG can detect all these features.

Taken together, these data indicate that the method described here is suitable for the detection of myelin and myelinated axons in the CNS and PNS. In addition, the gold stain detects the myelin sheaths of degenerating and newly emerging axons (Meier et al. 2004). Thus, this gold staining method allows for a wide range of applications ranging from developmental to regeneration studies. In summary, we provide here a staining method with a reliable general myelin dye that is suitable for histochemical staining concomitantly at the light and ultrastructural level.
Fig. 6 Distribution of goldphosphate-positive fibers in the shiverer mouse $\left(\mathrm{MBP}^{-/-}\right) \mathrm{mu}-$ tant. Longitudinal sections of the spinal cord at the thoracical level of a wildtype (WT) mouse (a) and a shiverer (SHI) mouse (b) stained with gold phosphate. BG-positive fibers are found in all white matter areas of the spinal cord (arrows scattered but concentrated gold staining). Bar $15 \mu \mathrm{m}$ (applies also to a)
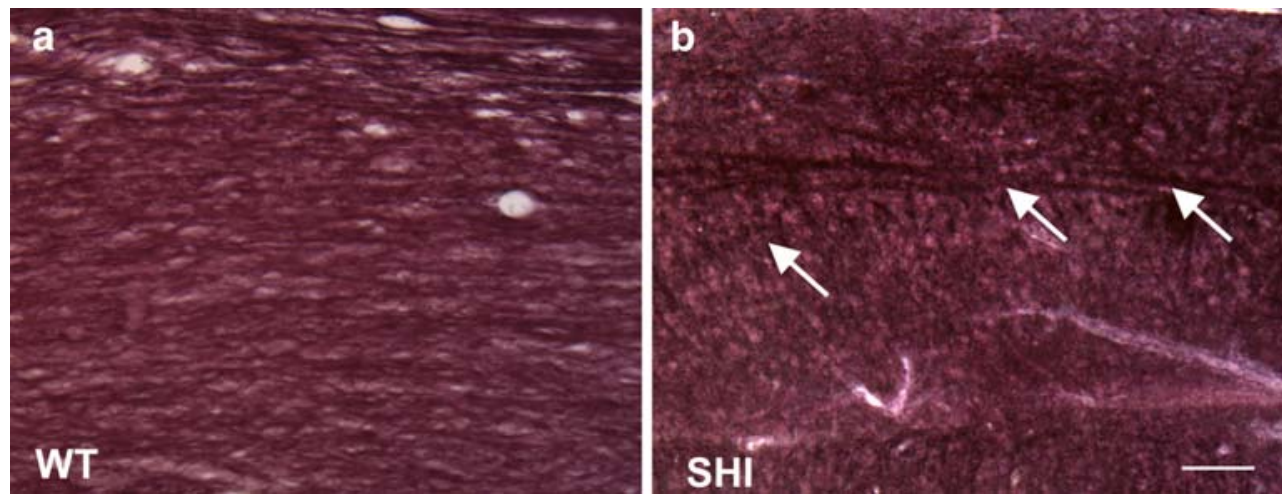
Acknowledgements The authors are grateful to Klaus-Armin Nave (MPI Göttingen, Germany) for providing the shiverer/MBP ${ }^{-/}$mouse strain and to Gary Matthews (State University of New York, USA) for providing optic nerve tissue.

\section{References}

Avila RL, Tevlin BR, Lees JP, Inouye H, Kirschner DA (2007) Myelin structure and composition in zebrafish. Neurochem Res 32:197-209

Bird TD, Farrell DF, Sumi SM (1978) Brain lipid composition of the shiverer mouse: (genetic defect in myelin development). J Neurochem 31:387-391

Cammer W, Norton WT (1976) Disc gel electrophoresis of myelin proteins: new observations on development of the intermediate proteins (DM-20). Brain Res 109:643-648

Campagnoni AT, Macklin WB (1988) Cellular and molecular aspects of myelin protein gene expression. Mol Neurobiol 2:41-89

Campagnoni AT, Campagnoni CW, Dutton GR, Cohen J (1976) A regional study of developing rat brain: the accumulation and distribution of proteolipid proteins. J Neurobiol 7:313-324

Chen MS, Huber AB, Haar ME van der, Frank M, Schnell L, Spillmann AA, Christ F, Schwib M (2000) Nogo-A is a myelinassociated neurite outgrowth inhibitor and an antigen for monoclonal antibody IN-1. Nature 403:434-439

Dou CL, Levine JM (1994) Inhibition of neurite growth by the NG2 chondroitin sulfate proteoglycan. J Neurosci 14:7616-7628

Dumont D, Noben JP, Moreels M, Vanderlocht J, Hellings N, Vandenabeele F, Lambrichts I, Stinissen P, Robben J (2007) Characterization of mature rat oligodendrocytes: a proteomic approach. J Neurochem 102:562-576

Dupouey P, Jacque C, Bourre JM, Cesselin F, Privat A, Baumann N (1979) Immunochemical studies of myelin basic protein in shiverer mouse devoid of major dense line of myelin. Neurosci Lett 12:113-118

Gallyas F (1979) Silver staining of myelin by means of physical development. Neurol Res 1:203-209

GrandPre T, Nakamura F, Vartanian T, Strittmatter SM (2000) Identification of the Nogo inhibitor of axon regeneration as a Reticulon protein. Nature 403:439-444

Greenfield S, Brostoff S, Eylar EH, Morell P (1973) Protein composition of myelin of the peripheral nervous system. J Neurochem 20:1207-1216

Henderson Z, Morris NP, Grimwood P, Fiddler G, Yang HW, Appenteng K (2001) Morphology of local axon collaterals of electrophysiologically characterised neurons in the rat medial septal/diagonal band complex. J Comp Neurol 430:410-432

Huber AB, Weinmann O, Brosamle C, Oertle T, Schwab ME (2002) Patterns of Nogo mRNA and protein expression in the developing and adult rat and after CNS lesions. J Neurosci 22:3553-3567

Jabonero V (1953) A new method for staining peripheral nervous elements. Z Mikrosk Anat Forsch 59(4):562-582

Kirschner DA, Ganser AL (1980) Compact myelin exists in the absence of basic protein in the shiverer mutant mouse. Nature 283:207-210

Kluver H, Barrera E (1953) Method for combined staining of cells and fibers in the nervous system. J Neuropathol Exp Neurol 12:400403

Kottis V, Thibault P, Mikol D, Xiao ZC, Zhang R, Derham P, Braun PE (2002) Oligodendrocytes-myelin glycoprotein (Omgp) is an inhibitor of neurite soutgrowth. J Neurochem 82:1566-1569

Lazzarini RA (2004) Myelin biology and its disorders. Elsevier, San Diego
Li M, Shibata A, Li C, Braun PE, McKerracher L, Roder J, Kater SB, David S (1996) Myelin-associated glycoprotein inhibits neurite/ axon growth and causes growth cone collapse. J Neurosci Res 46:404-414

McKerracher L, David S, Jackson DL, Kottis V, Dunn RJ, Braun PE (1994) Identification of myelin-associated glycoprotein as a major myelin-derived inhibitor of neurite growth. Neuron 13:805-811

Meier C (1976) Some observations on early myelination in the human spinal cord. Light and electron microscope study. Brain Res 104:21-32

Meier S, Brauer A, Heimrich B, Schwab ME, Nitsch R, Savaskan NE (2003) Molecular analysis of Nogo expression in the hippocampus during development and following lesion and seizure. FASEB J 17:1153-1155

Meier S, Brauer A, Heimrich B, Nitsch R, Savaskan NE (2004) Myelination in the hippocampus during development and following lesion. Cell Mol Life Sci 61:1082-1094

Morell P, Quarles RH, Norton WT (1994) Myelin formation, structure, and biochemistry. In: Siegel GJ, Agranoff BW, Albers RW, Molinoff PB (eds) Basic neurochemistry: molecular, cellular, and medical aspects. Raven, New York, pp $117-143$

Mukhopadhyay G, Doherty P, Walsh FS, Crocker PR, Filbin MT (1994) A novel role for myelin-associated glycoprotein as an inhibitor of axonal regeneration. Neuron 13:757-767

Niederost BP, Zimmermann DR, Schwab ME, Bandtlow CE (1999) Bovine CNS myelin contains neurite growth-inhibitory activity associated with chondroitin sulfate proteoglycans. J Neurosci 19:8979-8989

Pistorio AL, Hendry SH, Wang X (2006) A modified technique for high-resolution staining of myelin. J Neurosci Methods 15:135146

Prinjha R, Moore SE, Vinson M, Blake S, Morrow R, Christie G, Michalovich D, Simmons DL, Walsh FS (2000) Inhibitor of neurite outgrowth in humans. Nature 403:383-384

Privat A, Jacque C, Bourre JM, Dupouey P, Baumann N (1979) Absence of the major dense line in myelin of the mutant mouse "shiverer". Neurosci Lett 12:107-112

Schmued L, Slikker WJ (1999) Black-gold: a simple, high-resolution histochemical label for normal and pathological myelin in brain tissue sections. Brain Res 837:289-297

Rosenbluth J (1980) Central myelin in the mouse mutant shiverer. J Comp Neurol 194:639-648

Smith R (1992) The basic protein of CNS myelin: its structure and ligand binding. J Neurochem 59:1589-1608

Taylor CM, Marta CB, Claycomb RJ, Han DK, Rasband MN, Coetzee T, Pfeiffer SE (2004) Proteomic mapping provides powerful insights into functional myelin biology. Proc Natl Acad Sci USA 101:4643-4648

Trapp BD, Andrews SB, Wong A, O'Connell M, Griffin JW (1989) Co-localization of the myelin-associated glycoprotein and the microfilament components, F-actin and spectrin, in Schwann cells of myelinated nerve fibres. J Neurocytol 18:47-60

Uyemura K, Asou H, Takeda Y (1995) Structure and function of peripheral nerve myelin proteins. Prog Brain Res 105:311318

Wang KC, Koprivica V, Kim JA, Sivasankaran R, Guo Y, Neve RL, $\mathrm{He} Z$ (2002) Oligodendrocyte-myelin glycoprotein is a Nogo receptor ligand that inhibits neurite outgrowth. Nature 417:941944

Weigert C (1884) Ausfuehrliche Beschreibung der in Nr. 2 dieser Zeitschrift erwaehnten neuen Faerbungsmethode für das Zentralenervensystem. Fortschritte Med 2:190-194

Yiu G, He Z (2006) Glial inhibition of CNS axon regeneration. Nat Rev Neurosci 7:617-627 